Proceedings

\title{
Development of Microencapsulation Method of Gamma-Decalactone ${ }^{+}$
}

\author{
Jolanta Małajowicz ${ }^{1, *}$, Aleksandra Jedlińska ${ }^{2}$, Katarzyna Samborska ${ }^{2}$ and Amr Edris ${ }^{3}$ \\ 1 Department of Chemistry, Institute of Food Sciences, Warsaw University of Life Sciences-SGGW, \\ 159c Nowoursynowska str., 02-776 Warsaw, Poland \\ 2 Department of Food Engineering and Process Management, Institute of Food Sciences, Warsaw University \\ of Life Sciences-SGGW, 159c Nowoursynowska str., 02-776 Warsaw, Poland; \\ aleksandra_jedlinska@sggw.edu.pl (A.J.); katarzyna_samborska@sggw.edu.pl (K.S.) \\ 3 Department of Flavour and Aroma Chemistry, National Research Center, El Buhouth St., Dokki, \\ Cairo 12622, Egypt; amr_edris@hotmail.com \\ * Correspondence: jolanta_malajowicz@sggw.edu.pl; Tel.: +48-22-59-37-618 \\ + Presented at the 1st International Electronic Conference on Food Science and Functional Foods, \\ 10-25 November 2020; Available online: https://foods_2020.sciforum.net/.
}

Citation: Małajowicz, J.; Jedlińska, A.; Samborska, K.; Edris, A. Development of Microencapsulation Method of Gamma-Decalactone. Proceedings 2021, 70, 2. https://doi. org/10.3390/foods_2020-07660

Published: 9 November 2020

Publisher's Note: MDPI stays neutral with regard to jurisdictional claims in published maps and institutional affiliations.

Copyright: $\odot 2020$ by the authors. Licensee MDPI, Basel, Switzerland. This article is an open access article distributed under the terms and conditions of the Creative Commons Attribution (CC BY) license (http://creativecommons.org/licenses/by/4.0/).

\begin{abstract}
Microencapsulation is a technique that is increasingly used to encapsulate fragrances. It offers a valuable method to protect aromas against degradation in technological processes and during storage, which extends the usefulness of the aroma in the production and processing of food products. The aim of this research was to develop a microencapsulation method of gamma-decalactone, a cyclic ester with the scent of peach, which is used as a food additive. The carrier used for microencapsulation was an emulsion consisting of rapeseed oil, maltodextrin and gum Arabic. In this work, optimization of the carrier composition was performed in order to obtain a stable emulsion. The effect of inlet air temperature $\left(80^{\circ} \mathrm{C}, 180^{\circ} \mathrm{C}\right)$ during spray drying on the powder quality parameters was then analyzed. In the final stage, the gamma-decalactone content in the obtained powders was evaluated. The results showed that emulsions based on colza oil and gum Arabic are a good carrier for the microencapsulation of gamma-decalactone. The use of high pressure during homogenization results in better fragmentation and homogenization of the emulsion. Drying at a higher inlet air temperature $\left(180^{\circ} \mathrm{C}\right)$ contributes to a more efficient microencapsulation process in that more aroma is encapsulated inside the capsules with less adhering to their surface.
\end{abstract}

Keywords: microencapsulation; gamma-decalactone; spray drying

\section{Introduction}

Food flavors and aromas significantly influence consumers' decisions about everyday shopping. Almost every food and drink has distinct flavor and aroma profiles that are either natural or added in their composition. The food we choose every day would not be appealing to consumers if it did not have appropriate food flavors [1].

One of the fragrances commonly used by the food industry in flavor compositions is gamma-decalactone $\left(\mathrm{C}_{10} \mathrm{H}_{18} \mathrm{O}_{2}\right)$, a cyclic ester with peach and apricot scent. Gammadecalactone has GRAS (Generally Recognized As Safe) status and is considered a safe food additive, approved by the FDA (Food and Drug Administration). It is used widely in the production of beverages, bakery products, desserts and sweets, among others. In the cosmetics industry it is used in the production of perfumes, detergents, soaps, hairsprays, shampoos, creams and air fresheners [2].

Aromas are introduced into products in various forms, and one common delivery method is in the form of microcapsules. Microencapsulation is a technique that is increasingly used to encapsulate flavor and aroma compounds, and it enables the protection of 
aroma compounds against degradation in technological processes and during storage. The interaction of the aroma with other ingredients of the product is also limited. The microencapsulation process, by improving the functionality and stability of aromas, extends the scope of their application and ensures optimal dosing, which is important from an economic point of view for food and cosmetic producers [3].

In this study, microencapsulation of gamma-decalactone using spray drying was performed. Compositions of rapeseed oil, maltodextrin and gum Arabic were used as encapsulating wall materials. Some common parameters that determine the quality of the spraydried powder and the encapsulation efficiency of the gamma-decalactone were determined and optimized.

\section{Materials and Methods}

\subsection{Materials}

Gamma-decalactone ( $>98 \%$ ) was purchased from Sigma-Aldrich Chemical Co. (St Louis, MO, USA). Gum Arabic was obtained from Chempur (Piekary Śląskie, Poland), Maltodextrin (DE 15) from Pepees S.A. (Łomża, Poland) and rapeseed oil "Kujawski oil" from Kruszwica (Kruszwica, Poland).

\subsection{Gamma-Decalactone Emulsion Formulation}

An emulsion of gamma-decalactone was formulated as an initial step to microencapsulation using spray drying. The emulsion was formed by hydrating gum Arabic (GA) in deionized water to prepare a $30.0 \%$ w/v solution. Maltodextrin $(10 \% w / v)$, rapeseed oil $(1.5 \% w / v)$ and gamma-decalactone $(8.5 \% \mathrm{w} / \mathrm{v})$ were added to the solution. The whole mixture was magnetically stirred for $7.0 \mathrm{~min}$ at $385 \mathrm{rpm}$ to form a coarse pre-emulsion, which was then was homogenized for $5 \mathrm{~min}$ at 25,000 rpm using a homogenizer Ultra Turrax T25 (IKA Hielscher $\mathrm{GmbH}$, Berlin, Germany). One batch of the solution was subjected to an additional five times, two-stage pressure homogenization 250/50 MPa by using Panda Gea Niro Soavi homogenizer.

\subsection{Characterization of the Gamma-Decalactone Emulsion}

\subsubsection{Determination of Particle Size of the Emulsion}

Analysis of the particle size in the emulsion was performed using a particle size analyzer via a laser diffraction method (CILAS, Orléans, France). The determination was carried out in a closed-circuit wet dispersion whereby the dispersing liquid was distilled water. The emulsion was dosed into the equipment chamber in an amount which corresponded to an obscurance of about $10 \%$. The determination was performed immediately after obtaining the emulsion and after $24 \mathrm{~h}$ of storage at $4{ }^{\circ} \mathrm{C}$ in triplicate.

\subsubsection{Determination of Emulsion Stability}

The emulsion stability was determined using a Turbiscan apparatus (Lab ${ }^{\circledR}$ Expert Formulation SA, France). The vials were filled with the tested emulsion according to the manufacturer's instructions up to $75 \%$ of the vial height. The measurements were performed by scanning the vial every $40 \mu \mathrm{m}$. The determination was performed immediately after obtaining the emulsion and following $24 \mathrm{~h}$ of storage at $4{ }^{\circ} \mathrm{C}$. The TSI (Turbiscan Stability Index) was determined with the TurbiSoftLab 2.3.1.125 Turbiscan LabFormulaction software.

\subsection{Spray Drying Process}

The Mobile Minor Spray Dryer (GEA, Düsseldorf, Germany) equipped with a rotating disk to spray the feed solution was used with a rotation speed of $26,000 \mathrm{rpm}$. Two variants of drying were used: at an inlet air temperature of $80^{\circ} \mathrm{C}$ (dehumidified air spray drying-DASD powder) and $180^{\circ} \mathrm{C}$ (spray drying-SD powder), at maximum air humidity of $1 \mathrm{~g} / \mathrm{m}^{3}$. The air outlet temperature was $50{ }^{\circ} \mathrm{C}$ and $80{ }^{\circ} \mathrm{C}$ for the two variants respectively. The solutions were pumped to the disk at a speed of $0.3 \mathrm{~cm}^{3} / \mathrm{s}$; the rotational 
speed of the disk was $26,000 \mathrm{rpm}$. The dried powders were then stored at $4{ }^{\circ} \mathrm{C}$ prior to further analysis.

\subsection{Powder Morphology}

The gamma-decalactone powder morphology was analyzed using a field emission scanning electron microscope (FE-SEM, TM-3000 HITACHI) at an accelerating voltage of $10 \mathrm{kV}$. The powder was previously gold sputtered by being mounted on aluminum stubs with double-sided adhesive tape and coated with gold using an Edwards sputter coater S150A (Crawley, England).

\subsection{Extraction of Gamma-Decalactone from the Surface of Microcapsules}

In order to extract gamma-decalactone from the surface of microcapsules, $8 \mathrm{~g}$ of individual powders (SD and SADS) were weighed. The powders were transferred to a square piece of blotting paper $(15 \times 15 \mathrm{~cm})$, and the ends of the paper were folded to emulate an extraction thimble before being placed in the Soxhlet apparatus. A volume of $150 \mathrm{~cm}^{3}$ of methylene chloride was poured into a $250 \mathrm{~cm}^{3}$ round-bottom flask, and the extraction kit was assembled. After 6 overflows of the solvent, the heating was turned off and the solutions allowed to cool prior to being transferred into a conical flask and drying with magnesium sulfate for approximately $10 \mathrm{~min}$. The solutions were then passed through a fluted filter into a tared flask of $250 \mathrm{~cm}^{3}$. The methylene chloride was distilled off on an evaporator, the flask was reweighed and the mass of the gamma-decalactone remaining was calculated.

\subsection{Determination of Gamma-Decalactone Concentration}

The concentration of gamma-decalactone in the analyzed samples (reconstituted emulsions and powders were verified by gas chromatography (YL6001 Chromatograph, Young Lin Instrument-BPX70 capillary column: $30 \mathrm{~m} \times 0.25 \mathrm{~mm}$ )) was determined using the following temperature program: holding for $1 \mathrm{~min}$ at $165^{\circ} \mathrm{C}$, followed by a temperature rise from $165^{\circ} \mathrm{C}$ to $180^{\circ} \mathrm{C}$ at a rate of ${ }^{\circ} \mathrm{C} / \mathrm{min}$ and a final temperature increase from $180^{\circ} \mathrm{C}$ to $205^{\circ} \mathrm{C}$ at a rate of $5{ }^{\circ} \mathrm{C} / \mathrm{min}$.

\section{Results and Discussion}

The results of emulsion particle size analyses obtained as a result of two different variants of homogenization and $24 \mathrm{~h}$ storage are summarized in Figure 1a. The graphs show the particle diameter distribution in individual emulsions.

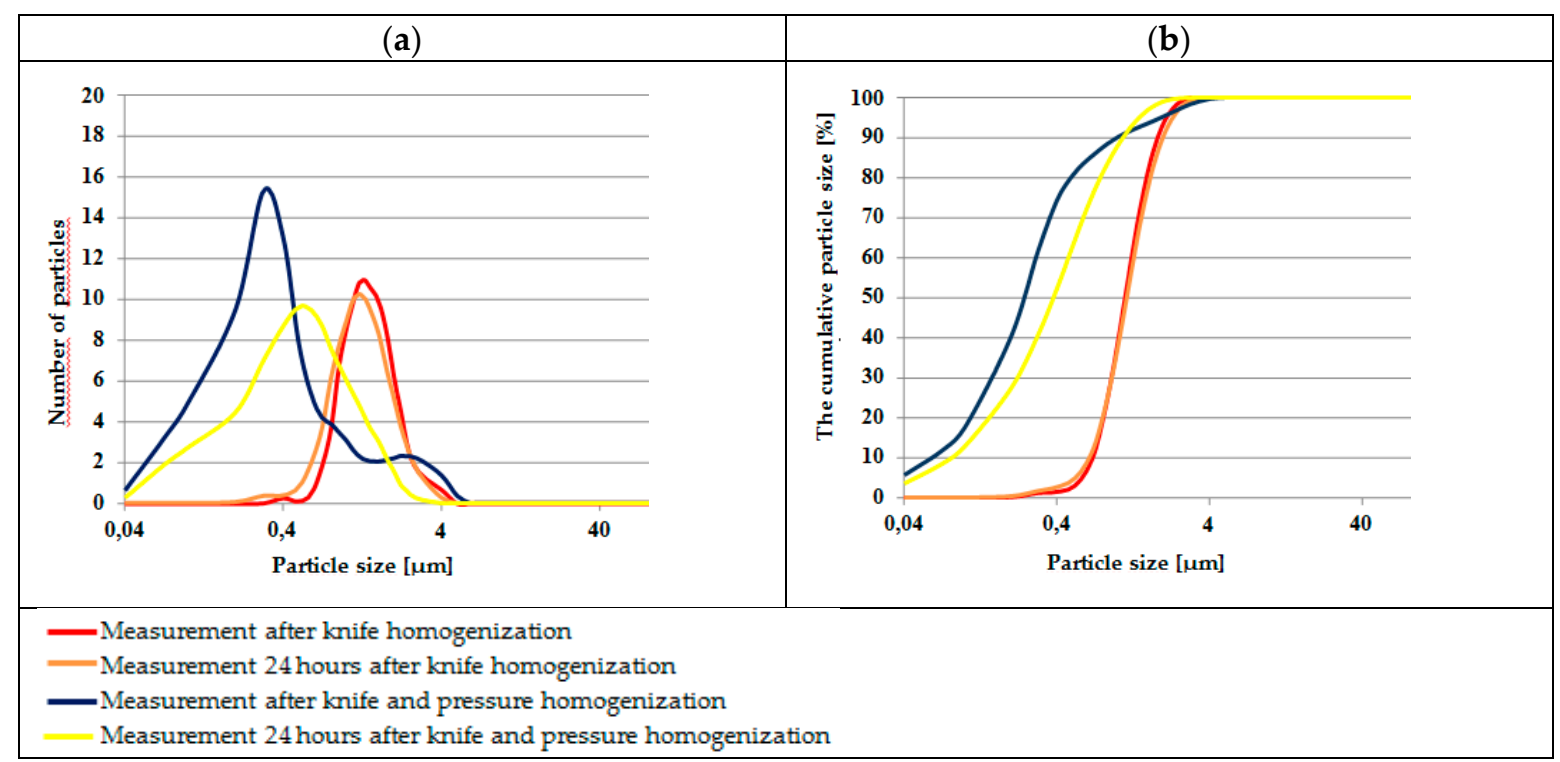

Figure 1. Particle size distribution (a) and cumulative curves of emulsion particle size distributions (b). 
The data show that after knife and pressure homogenization, the emulsion was characterized by significantly smaller particle diameters compared to the solution subjected only to knife homogenization. The largest population in the first variant were particles with a diameter of $0.3 \mu \mathrm{m}$, and in the second variant $1.4 \mu \mathrm{m}-$ i.e., approximately 5 times larger. When knife homogenization was used, the $24 \mathrm{~h}$ storage of the emulsion did not change the particle size distribution in the homogenate. In both emulsions, the main population consisted of particles ranging in diameter from $0.6-3 \mu \mathrm{m}$. The most numerous particles were 1.2-1.4 $\mu \mathrm{m}$ in diameter. A clear difference in the population of particles after $24 \mathrm{~h}$ storage could be observed in emulsions after pressure homogenization. As a result of storage, the proportion of larger-diameter particles in the emulsion increased. The largest population in this solution were particles with a diameter of $0.6 \mu \mathrm{m}$, while particles with a size of $0.3 \mu \mathrm{m}$ dominated in the fresh emulsion.

The cumulative particle size distribution curve shown in Figure $1 \mathrm{~b}$ confirms that the emulsion subjected only to knife homogenization showed a higher content of particles with larger sizes $-90 \%$ of the population were particles with sizes from 0.4 to $2 \mu \mathrm{m}$. For comparison, in emulsions after knife homogenization and pressure homogenization, $90 \%$ of the population were particles in the $0.04-1 \mu \mathrm{m}$ range, which is $2-10$ times smaller. The $24 \mathrm{~h}$ storage of the emulsion after pressure treatment shifted the cumulative curve towards larger particles. According to Kowalska et al. [4], during the storage of emulsions, regardless of the temperature (room or cooling), an increase in the average particle size is usually observed.

The basic study of the obtained emulsion system was the analysis of its stability. The results of stability measurements of the tested emulsions in the form of backscattered light intensity profiles $(\triangle R W)$ are shown in Figure 2.

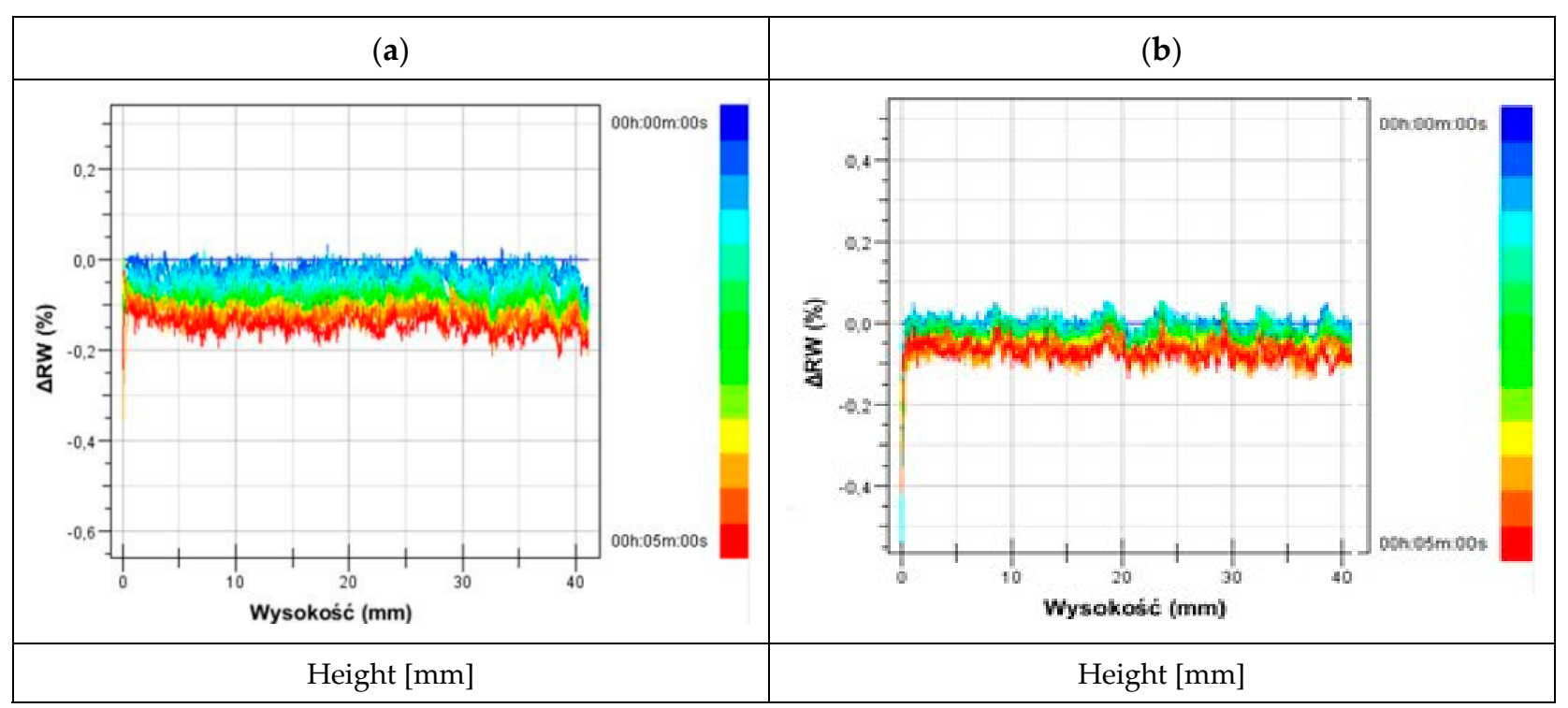

Figure 2. Profile of the scattered light intensity changes $(\triangle \mathrm{RW})$ for the emulsion after knife homogenization (a) and after knife and pressure homogenization $(\mathbf{b})$.

Changes in the intensity of backscattered light $(\Delta R W)$ depending on the height of sample layers in the measuring vessel correspond to changes in the microstructure of the colloidal solution, the movement of particles of the dispersed phase and the changes in the size of particles. The TSI describes the stability of the mixture, where an increase in TSI corresponds with an emulsion that is less stable. Emulsion instability is typically the result of two distinct physical processes: particle size expansion associated with coalescence or flocculation and particle migration leading to creaming or sedimentation. The turbidimetric method of examining the stability of dispersion systems enables detection of these phenomena at a very early stage [5]. 
Following measurement over a 5 min period, it was observed that the level of the backscattered light (Figure 2) remained relatively constant. Therefore, there was no coalescence or flocculation, i.e., physico-chemical phenomena that contribute to the increase in particle diameter in the entire sample volume. On the basis of the graphs in Figure 2, it can be concluded that the emulsion immediately after knife and pressure homogenization was more uniform, and the material was characterized by slightly higher homogeneity. The corresponding TSI values (Figure 3 ) are relatively low, and close to zero. In the entire sample volume, the emulsion was very stable, and the differences between the emulsions after one homogenization (knife) process and after two homogenization (knife and pressure) processes were insignificant.

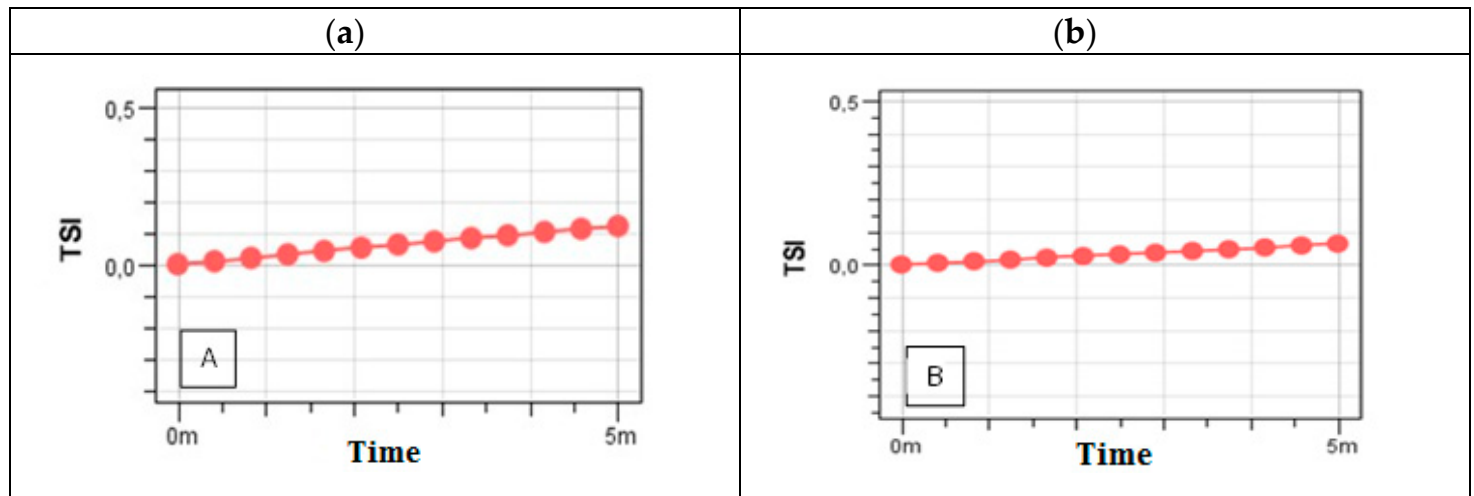

Figure 3. Change in the Turbiscan Stability Index (TSI) Global index (general) in the period of 5 min for the emulsion after knife homogenization (a) and after knife and pressure homogenization (b).

Microscopic images of the "dry emulsions" powders were taken to observe changes in morphology (Figure 4).

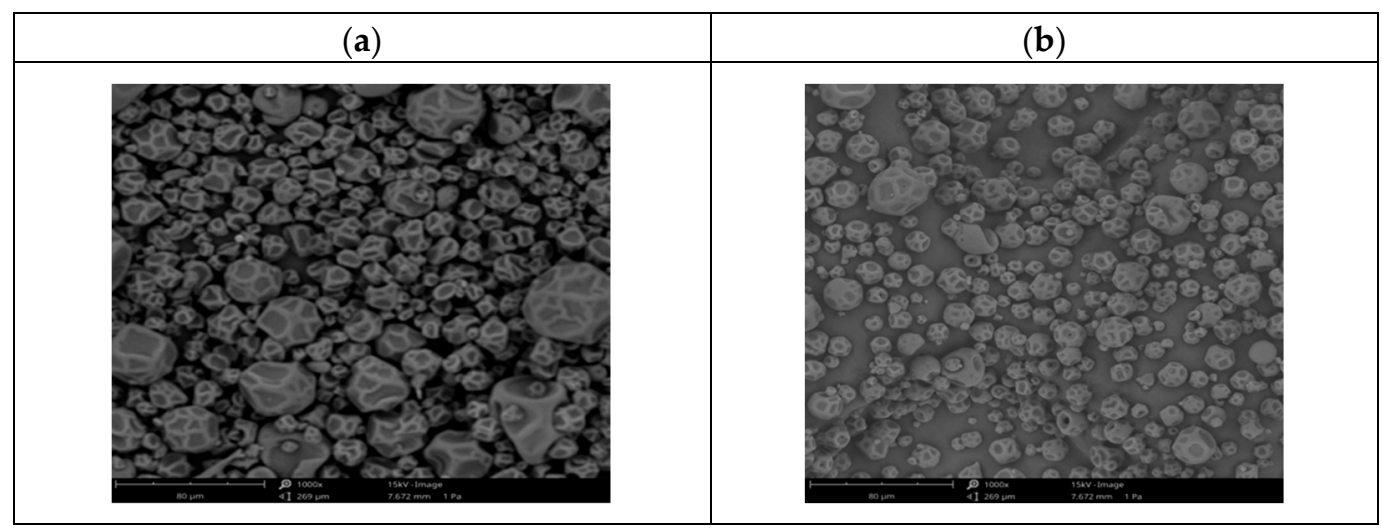

Figure 4. Morphology of SD (a) and DASD (b) powders dried at $180^{\circ} \mathrm{C}$ and $80^{\circ} \mathrm{C}$, respectively.

The images show some differences in the morphology of the powders following the different treatments. The SD powder particles (Figure 4a) were more irregular in shape, and their structure was wrinkled. There was also a significant difference in particle size distribution. The structures of DASD powder (Figure $4 \mathrm{~b}$ ) were rounder and had a smoother shell, and their size was less varied. In the images of both powders, there were no visible sticky particles merging into larger clusters. The noticeable difference in the surface appearance of powder particles is probably due to the different temperature of the inlet air used for drying emulsions. In the SD powder (dried at higher temperature), the particles are more tightly packed, although they appear larger. In the DASD powder, the spaces between the powder particles are clearly larger. Both sets of SEM images revealed roughness on capsule surfaces. Such imperfections are formed when there is a slow process of film formation during the drying of the atomized droplets [6]. 
The gamma-decalactone concentration in emulsions and powders was determined by gas chromatography after extraction with dichloromethane. When comparing the gamma-decalactone content in powders as a function of the different treatments, a clear difference in the aroma concentration can be observed (Table 1).

Table 1. Gamma-decalactone concentration in emulsion and powders.

\begin{tabular}{ccc}
\hline $\begin{array}{c}\text { Emulsion before the } \\
\text { Drying Process } \\
{\left[\mathrm{g} / \mathbf{d m}^{3}\right]}\end{array}$ & $\begin{array}{c}\text { Emulsion Reconstituted } \\
\text { from SD Powder } \\
{\left[\mathrm{g} / \mathbf{d m}^{3}\right]}\end{array}$ & $\begin{array}{c}\text { Emulsion Reconstituted from } \\
\text { DASD Powder } \\
{\left[\mathrm{g} / \mathbf{d m}^{3}\right]}\end{array}$ \\
\hline $57.76 \pm 1.57$ & $43.04 \pm 0.39$ & $30.26 \pm 0.44$ \\
\hline
\end{tabular}

A higher concentration of gamma-decalactone was observed in SD powder dried at a higher temperature (air inlet temperature at $180^{\circ} \mathrm{C}$ ). Nevertheless, the process of microencapsulation of the compound contributes to a decrease in its concentration in reconstituted emulsions. In the case of the above experiment, the decrease was from $25 \%$ (for SD powder) to $47.6 \%$ (for DASD powder). Other studies have reported that the concentration of aroma in microcapsules is correlated with an increase of the carrier content in the solution, and thus with an increase in emulsion viscosity. In most cases, an increase in viscosity increases the amount of entrapped flavor, but only up to a certain optimum viscosity level for a given carrier [7]. It is also believed that the increase in the apparent density of powders and the particle diameter of the $\mathrm{d}_{50}$ powders is associated with greater efficiency of flavor encapsulation [8].

Given the possibility of deposition of the aroma compound on the outer surfaces of the microcapsules, the concentration of gamma-decalactone in the extracts obtained from the Soxhlet extraction of the SD and DASD powders was also analyzed (Table 2).

Table 2. Gamma-decalactone concentration in extracts from the surface of powders.

\begin{tabular}{cc}
\hline $\begin{array}{c}\text { SD Powder Surface Extract } \\
{\left[\mathbf{g} / \mathbf{d m}^{3} \text { for } \mathbf{1} \mathbf{g} \text { of Powder] }\right.}\end{array}$ & $\begin{array}{c}\text { DASD Powder Surface Extract } \\
\text { [g/d } \mathbf{d m}^{3} \text { for } \mathbf{1} \mathbf{~} \text { of Powder] }\end{array}$ \\
\hline $0.038 \pm 0.003$ & $0.271 \pm 0.016$ \\
\hline
\end{tabular}

The results obtained from GC analyses of the extracts showed that gamma-decalactone is present on the surface of the microcapsules of both powders. Over 7 times more gamma-decalactone was deposited on the surface of DASD powder microcapsules compared to the surface of the SD powder. Gamma-decalactone adhesion to the surface of microcapsules is the result of a number of physical parameters of the powders.

Author Contributions: Conceptualization, J.M., K.S. and A.J.; methodology, K.S., A.J. and A.E.; resources, J.M., K.S. and A.J.; writing-original draft preparation, J.M.; writing-review and editing, J.M.; visualization, J.M.; supervision, K.S. All authors have read and agreed to the published version of the manuscript.

Funding: This research received no external funding.

Conflicts of Interest: The authors declare no conflict of interest.

\section{References}

1. Parker, J.K.; Elmore, S.; Methven, L. Flavour Development, Analysis and Perception in Food and Beverages; Woodhead Publishing Series in Food Science, Technology and Nutrition; Woodhead Publishing, London, UK, 2015; pp. 3-30.

2. Gopinath, M.; Vijayakumar, L.; Dhanasekar, R.; Viruthagiri, T. Microbial biosynthesis of $\gamma$-decalactone and its applications-a review. Glob. J. Biotechnol. Biochem. 2008, 3, 60-68.

3. Ozkan, G.; Franco, P.; De Marco, I.; Xiao, J.; Capanoglu, E. A review of microencapsulation methods for food antioxidants: Principles, advantages, drawbacks and applications. Food Chem. 2019, 272, 494-506.

4. Kowalska, M.; Żbikowska, A.; Śmiechowski, K.; Marciniak-Łukasiak, K. Effect of sunflower lecithin quantity and homogenization time on stability of food emulsion containing walnut oil. Żywność. Nauka. Technologia. Jakość 2014, 1, 78-91. (In Polish) 
5. Mengual, O.; Meunier, G.; Cayre, I.; Puech, K.; Snabre, P. Characterisation of instability of concentrated dispersions by a new optical analyzer: The Turbiscan MA 2000. Colloids Surfaces A Physicochem. Eng. Asp. 1999, 152, 111-123.

6. Re, I. Microencapsulation by spray drying. Drying Technol. 1998, 16, 1195-1236.

7. Fernandes, L.P.; Turatti, I.C.C.; Lopes, N.P.; Ferreira, J.C.; Candido, R.C.; Oliveira, W.P. Volatile retention and antifungal properties of spray-dried microparticles of Lippia sidoides essential oil. Drying Technol. 2008, 26, 1534-1542.

8. Janiszewska, E.; Arciszewska, M.; Witrowa-Rajchert, D. Zależność między efektywnością mikrokapsułkowania aromatu wanilinowego i właściwościami fizycznymi uzyskanych proszków. Żywność. Nauka. Technologia. Jakość 2013, 3, $174-186$. 